\title{
Evaluation of E-Commerce Website Functionality Using a Mamdani Fuzzy System
}

$\begin{array}{cc}\text { L. Al-Qaisi } & \text { A. Mesleh } \\ \text { The World } & \text { Computer } \\ \text { Islamic } & \text { Engineering } \\ \text { Sciences \& } & \text { Dpt, Al-Balqa } \\ \text { Education } & \text { Applied } \\ \text { University } & \text { University, } \\ \text { Amman, } & \text { Amman, Jordan } \\ \text { Jordan } & \text { wadood@ } \\ \text { laila.qaisi@ } & \text { fet.edu.jo } \\ \text { gmail.com } & \end{array}$

\author{
A. Al-Qaisi \\ Communication \\ Technology \\ Engineering Dpt, \\ Al-Balqa \\ Applied \\ University, \\ Amman, Jordan \\ Aws.alqaisi@ \\ bau.edu.jo
}

\author{
A. Sharadqh \\ Computer \\ Engineering \\ Dpt, Al-Balqa \\ Applied \\ University, \\ Amman, \\ Jordan \\ dr.ahmed.shara \\ dqah@ \\ bau.edu.jo
}

\author{
B. Zahran \\ Computer \\ Engineering \\ Dpt, Al-Balqa \\ Applied \\ University, \\ Amman, \\ Jordan \\ zahranb@ \\ bau.edu.jo
}

\author{
J. Alkasassbeh \\ Electrical \\ Engineering Dpt, \\ Al-Balqa \\ Applied \\ University, \\ Amman, Jordan \\ jawdat1983@ \\ bau.edu.jo
}

\author{
M. Olaimat \\ Communication \\ Technology \\ Engineering Dpt, \\ Al-Balqa Applied \\ University, \\ Amman, Jordan \\ olaimat@ \\ bau.edu.jo
}

\begin{abstract}
The majority of leader companies are running their businesses using online E-commerce websites. These E-commerce websites are becoming significant revenue drivers and major retailers. Hence, it is critical to evaluate the functionality of these websites which are expected to support growing business needs. The evaluation of the functionality of E-commerce websites is not a straightforward process due to the many constraints and standards that should be considered. Fuzzy logic is a powerful technique used in modeling impreciseness and uncertainties. This paper proposes a Mamdani fuzzy system that evaluates the functionality of E-commerce websites over different parameters: accuracy, flexibility, client support, and availability of product information. Experimental results provide positive relations between accuracy and flexibility on the functionality of $E$ commerce websites.
\end{abstract}

Keywords--commerce websites; Mamdani Fuzzy system; Websites functionality

\section{INTRODUCTION}

The use of internet affects the world of business in various aspects. International trend goes towards using e-media in conducting many business functions, through easy to use websites (especially for multinational companies). Nowadays, multinational companies focus on having such portals and websites to serve their customer needs and to simplify procedures of purchasing their products. Ecommerce gains attention as it helps in achieving better price, improved quality and customer satisfaction with lower costs. This attention is growing as more facilities are introduced in the field [1].

Many researchers have conducted various studies focusing on websites characteristics. These characteristics influence clients' impression of the companies' portals. For clients, any company website represents a connection tool between them and the company and affects their behavior, beliefs and intentions. Also, companies are much aware of the power of Word of Mouth (WOM) which has a great impact on their reputation especially with the current increased usage of social networking portals [2]. In [3], authors concluded that many commercial websites characteristics such as precise information, loading speeds, interactivities, graphics, colors, accessibility and ease of usage are well studied. However, less focus is paid to the firm's interactivity with clients via their websites. It's important for any organization to assess their Ecommerce website to improve their services and to achieve their goals as well as getting competitive among their peers [4]. Most of working companies across the world has already adopted E-Commerce and has created online websites [5]. Also, researchers in the field of E-Commerce have agreed on the increased use of Internet in commercializing products [3]. Moreover, the demand of customers of online shopping to get the desired products in an easy and quality guaranteed way has been increased rapidly.

It is obvious that the Internet and information technology (IT) revolution has created a new business environment which differs from the previous ones and has motivated the need to establish an effective measurement for E-Commerce websites' quality. It is also clear that the majority of previous studies on the quality of E-Commerce websites and their characteristics have failed to address the direct relation between functionality and quality of E-Commerce websites. Many researches have adopted the theory of fuzzy sets and expert systems in various applications including E-commerce. Many of the fuzzy expert systems that are used in E-commerce applications focused on models that assessed security, trust and privacy aspects of Ecommerce websites [6-9]. Some researcher also studied the quality of E-commerce websites [10-13]. However, the quality of E-commerce has not been studied separately. This paper proposes a Mamdani type of fuzzy system to assess E- 
Commerce website functionalities and their role in ECommerce website quality.

In [14], the authors constructed a model to evaluate the quality of E-Commerce websites depending on several aspects such as the usability, conceptual reliability and representation reliability. In their study, the degree of functionality is logically found to be an effective factor on quality of any website. Hence, it affects an E-Commerce website's quality as well as it plays vital role in its performance. In [9], the authors described a fuzzy system which allows users to encode knowledge needed for specialists' thinking to solve complex problems such as assessing the functionality of an E-Commerce website. Furthermore, in [12], the authors found that assessment process is neither familiar with normal peoples' logic nor traditional Boolean logic and they introduced a fuzzy expert system. In [15], the author discussed the characteristics of online shopping websites from 2006 to 2011. Nevertheless, he did not investigate the functionality factor.

This paper fills the gap of assessing E-Commerce website functionalities and their role in E-Commerce websites' quality using Mamdani fuzzy system. The theory of fuzzy logic is based on the concept of relative graded membership, as inspired by the processes of human perception and cognition [16]. Fuzzy logic usually deals with information arising from computational models, that is, uncertain, imprecise, vague, partially true, or without sharp boundaries. Fuzzy logic is considered extremely useful for a wide range of applications such as facial pattern recognition, air conditioners, washing machines, vacuum cleaners, antiskid braking systems, transmission systems, control of subway systems and unmanned helicopters, knowledge-based systems for multiobjective optimization of power systems, weather forecasting systems, models for new product pricing or project risk assessment, medical diagnosis and treatment plans, consumer electronics, image processing and stock trading [16].

\section{THE PROPOSED MAMDANI FUZZY SYSTEM}

Figure 1 illustrates the general steps of implementing the proposed Mamdani fuzzy system model to assess E-Commerce websites' functionalities and their role in E-Commerce websites' quality [17-19]:

- The problem of assessing E-Commerce website functionalities is described.

- Four linguistic variables (fuzzy logic operating parameters) are chosen for input parameters namely: accuracy, flexibility, client support and availability of product information. One linguistic variable is chosen for output namely functionality.

- A fuzzy set and membership functions for each linguistic variable are set based on initial knowledge and modified several times during tuning stages.

- The linguistic ranges and values for the linguistic variables are specified (see Table 1). Moreover, the membership functions and the associated values for each parameter are initialized in Fig.2-4.
- The rules for the fuzzy logic system are constructed that use input membership values as weighting factors to determine their influence on the fuzzy output set. Some of these rules are:

Rule 1: $($ Accuracy==low) $\mid$ (Flexibility==low) =>

(Functionality $=$ Weak)

Rule 2: (Accuracy==Moderate) $\mid$ (Flexibility==

Moderate $)=>$ (Functionality $=$ Moderate)

Rule 3: (Accuracy==High) $\mid$ (Flexibility==Strong) =>

(Functionality $=$ Strong)

Rule 4: (Client Support==low) \& (Availability of Product Information $==$ low $)=>$ (Functionality $=$ Weak)

Rule 5: (Client Support==Moderate) \& (Availability of Product Information $==$ Moderate $)=>$ (Functionality

$=$ Moderate)

Rule 6: (Client Support==High) \& (Availability of

Product Information==High) $=>$ (Functionality $=$ Strong)

- The parameters of the fuzzy system (such as the number of membership functions and their shapes, linguistic variables ranges and values) and fuzzy rules undergo through a tuning stage that modifies them several times before getting stabilized.

- The fuzzy model is coded and ready to be tested. A Mamdani fuzzy method is used to infer the proposed model.

- The inference process begins with the fuzzification stage which coverts crisp inputs to fuzzy values.

- The fuzzy values are projected into the fuzzy rules.

- The outputs of each rule are combined using MIN-MAX method.

- The aggregated fuzzy output is defuzzified using fuzzy centroid method.

- Finally, the results of functionality of the E-commerce website are evaluated.

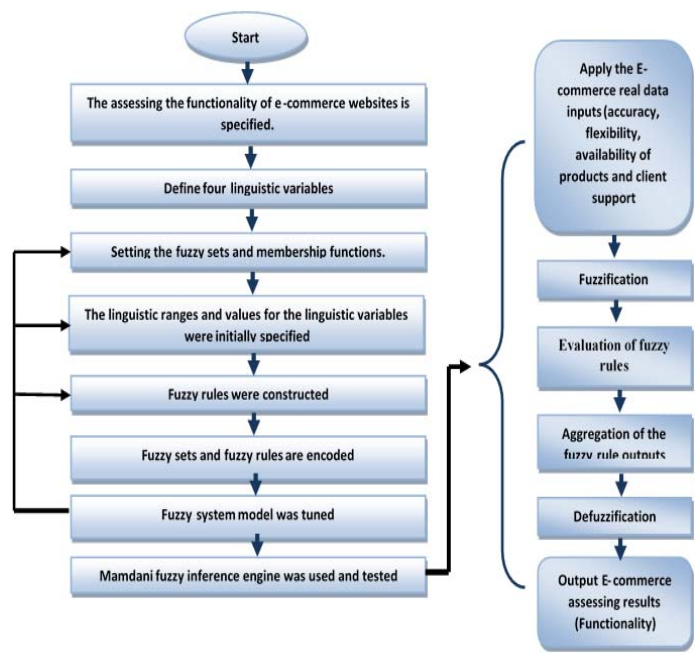

Fig. 1. Steps of designing the Mandani fuzzy system 
TABLE I. RANGES AND VALUES FOR THE LINGUISTIC VARIABLES.

\begin{tabular}{|c|c|c|c|}
\hline \multirow{4}{*}{ Accuracy } & $\begin{array}{c}\text { Linguistic } \\
\text { values }\end{array}$ & Notation & $\begin{array}{c}\text { Normalized } \\
\text { numerical } \\
\text { ranges }\end{array}$ \\
\hline \multirow{3}{*}{ Flexibility } & Low & $\mathrm{L}$ & $0-0.4$ \\
\cline { 2 - 4 } & Hoderate & $\mathrm{M}$ & $0.3-0.7$ \\
\cline { 2 - 4 } & Low & $\mathrm{H}$ & $0.65-1$ \\
\cline { 2 - 4 } & Strong & $\mathrm{L}$ & $0-0.4$ \\
\hline \multirow{3}{*}{$\begin{array}{c}\text { Client support } \\
\text { Availability of }\end{array}$} & Low & $\mathrm{M}$ & $0.3-0.7$ \\
\cline { 2 - 4 } & Moderate & $\mathrm{M}$ & $0.65-1$ \\
\cline { 2 - 4 } & High & $\mathrm{H}$ & $0-0.4$ \\
\cline { 2 - 4 } & Low & $\mathrm{L}$ & $0.65-1$ \\
\cline { 2 - 4 } & Moderate & $\mathrm{M}$ & $0-0.4$ \\
\hline \multirow{3}{*}{ Functionality } & High & $\mathrm{H}$ & $0.6-0.7$ \\
\cline { 2 - 4 } & Weak & $\mathrm{W}$ & $0-0.4$ \\
\cline { 2 - 4 } & Moderate & $\mathrm{M}$ & $0.3-0.7$ \\
\hline
\end{tabular}

\section{RESULTS}

The proposed Mamdani fuzzy system was coded using MATLAB which offers a fuzzy logic toolbox. Figure 2 shows the effect of accuracy on the functionality of E-commerce websites. In Figure 2, it is clear that functionality is lowest when accuracy is minimum. However, functionality is most excellent when accuracy is maximum. It is clear that functionality is stable when the accuracy is between 5 and 10 (averaged values). Moreover, Figure 3 shows that the functionality of E-commerce websites increases as flexibility is increasing. Figure 4a shows the effect of accuracy combined with client support on functionality of E-commerce websites. Figure 4b shows the effect of accuracy combined with product information. From Figure 4, it can be concluded that client support and availability of product information have low effect on the functionality of E-commerce website.

Figure 5 a shows the effect of flexibility combined with client support. Figure 5b shows the effect of flexibility combined with the availability of product information on the functionality of E-commerce website. From Figure 5, it can be concluded that the flexibility combined with client support/availability of product information has low effect on the functionality of E-commerce websites.

Finally, Figure 6 plots the surface diagram of our proposed Mamdani fuzzy system and describes the flexibility effect on the accuracy combined with the flexibility effect on the functionality of E-commerce websites. It can be concluded from Figure 9 that the functionality is lowest at low accuracy and flexibility levels. On the other hand, the functionality is highest at the maximum levels of accuracy. It can be concluded that the surface graph in Figure 6 indicates a positive effect between the degree of accuracy, the flexibility and the functionality of E-Commerce websites. Furthermore, other functionality values vary when changing the accuracy and flexibility.

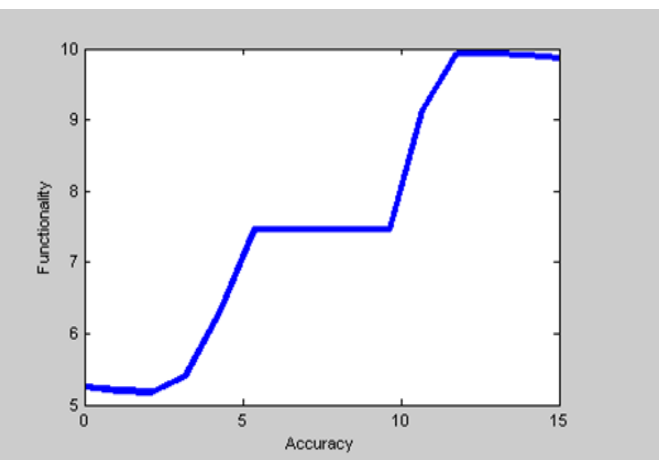

Fig. 2. Accuracy effect on E-commerce websites functionality

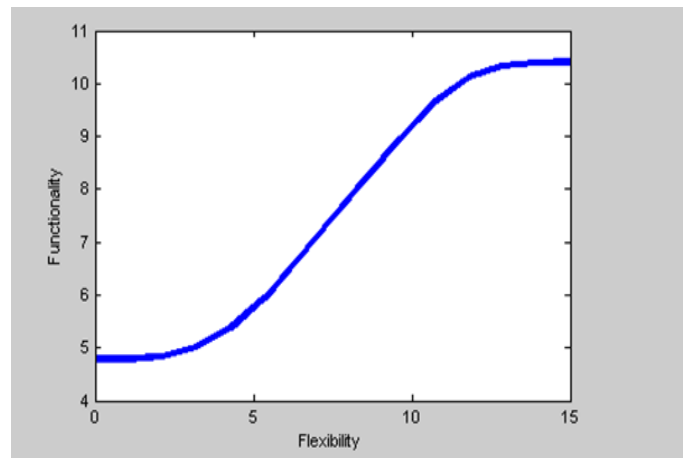

Fig. 3. Flexibility effect on E-commerce websites functionality

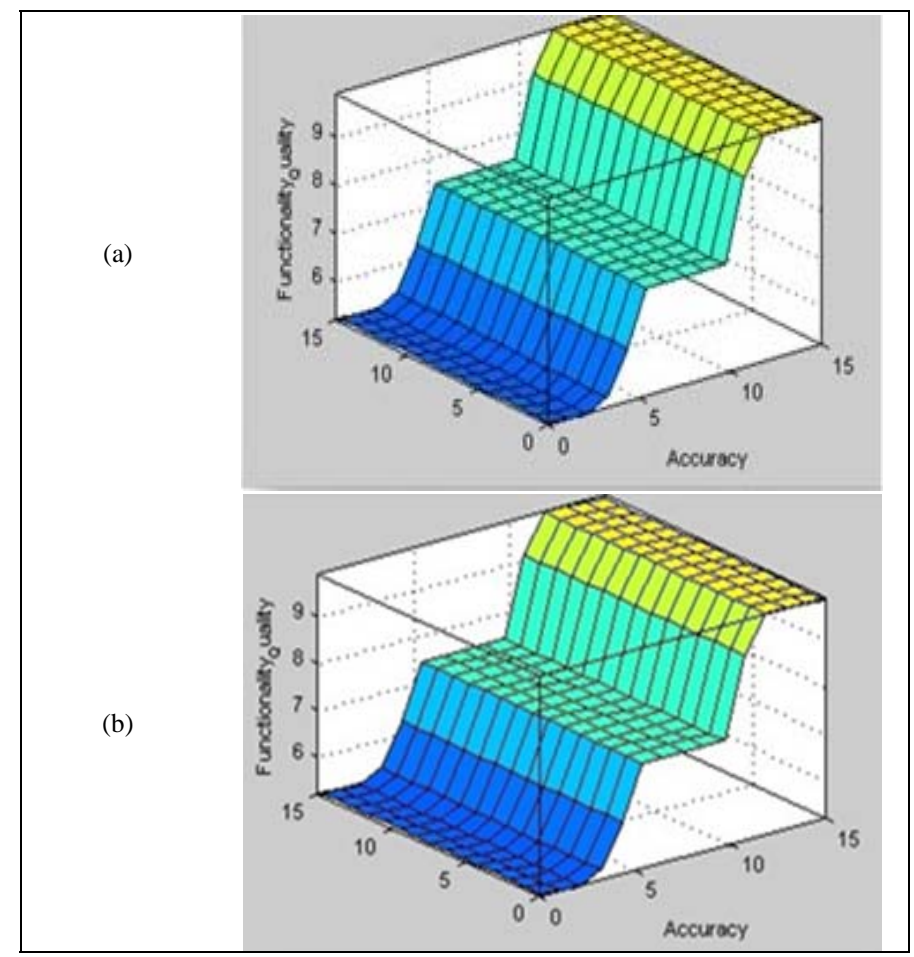

Fig. 4. Effect of accuracy combined with (a) client support and (b) availability of product information on functionality of E-commerce websites. It should be noted that the other dimensions in (a) and (b) are the client support and the availability of product support respectively 
(a)

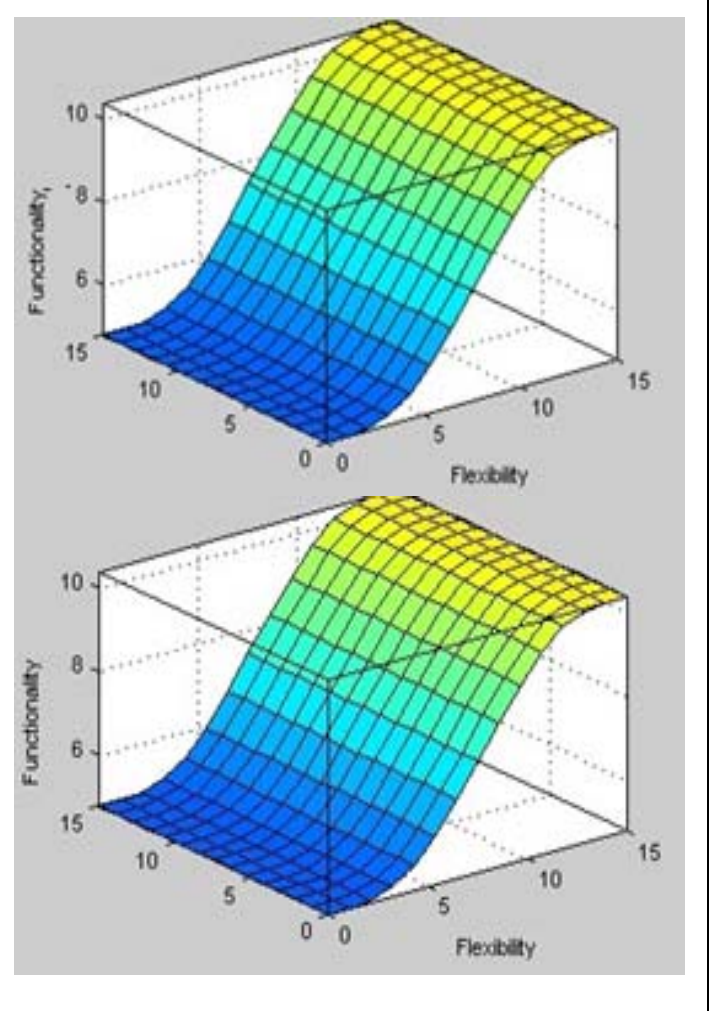

Fig. 5. Effect of flexibility combined with client support and availability of product information on functionality of E-commerce websites. Note that the other dimensions in (a) and (b) are the client support and the availability of product support respectively

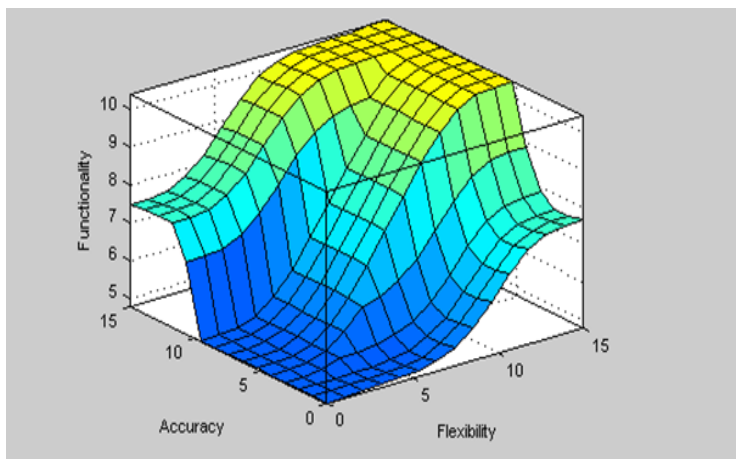

Fig. 6. Plot of Surface that shows the effect of accuracy combined with flexibility on functionality of E-commerce websites

\section{CONCLUSION}

Many researchers have authored various studies focusing on websites characteristics. These characteristics influence clients' impression of the companies' portals. As increased functionality has a positive effect on the quality of an ECommerce website, we implemented and tested a Mamdani fuzzy system that evaluates the effect of accuracy, flexibility, product availability and client support on the functionality of E-commerce websites. It was concluded that accuracy and flexibility are the most effective variables regarding the functionality of an E-Commerce website. The availability of product information and client support however had fixed effect on Functionality.

\section{REFERENCES}

[1] S. Mariotti, F. Sgobbi, “Alternative paths for the growth of ecommerce”, Futures, Vol. 33, No. 2, pp. 109-125, 2001

[2] C. Chan, P. Swatman, "Management and business issues for B2B eCommerce implementation”, 35th Hawaii International Conference on System Sciences, pp. 3083-3093, Big Island, Hawaii, January 7-10, 2002

[3] B. Hernández, J. Jiménez, M. José Martín, "Key website factors in ebusiness strategy", International Journal of Information Management, Vol. 29, No. 5, pp. 362-371, 2009

[4] L. Mich, M. Franch, L. Gaio, "Evaluating and Designing Web Site Quality”, IEEE Multimedia, Vol. 10, No. 1, pp. 34-43, 2003

[5] D. Sui, D. Rejeski, "Environmental impacts of the emerging digital economy: the e-for-environment e-commerce?”, Environmental Management, Vol. 29, No. 2, pp. 155-163, 2002

[6] N. Griffiths, K. Chao, M. Younas, "Fuzzy Trust for Peer-to-Peer Systems", 26th IEEE International Conference on Distributed Computing Systems Workshops, Lisboa, Portugal, July 04-07, 2006

[7] X. Xiu-yan, "A Fuzzy Cluster Model for Evaluating E- commerce Trust”, 4th International Conference on Management of e-Commerce and e-Government, pp. 60-64, Chengdu, China, October 23-24, 2010

[8] O. Signore, “A comprehensive model for web sites quality”, 7th IEEE International Symposium on Web Site Evolution, pp. 30-36, Budapest, Hungary, September 26, 2005

[9] F. Akhter, D. Hobbs, Z. Maamar, "A fuzzy logic-based system for assessing the level of business-to-consumer (B2C) trust in electronic commerce”, Expert Systems with Applications, Vol. 28, No. 4, pp. 623628, 2005

[10] J. Zhang, X. Guo, “Trust Evaluation Model Based on Fuzzy Logic for C2C E-Commerce”, 1st International Symposium on Information Engineering and Electronic Commerce, pp. 403-407, Ternopil, Ukraine, May 16-17, 2009

[11] M. Nilashi, K. Bagherifard, O. Ibrahim, N. Janahmdi, M. Barisami, “An Application Expert System for Evaluating Effective Factors on Trust in B2C Websites”, Engineering, Vol. 3, No. 11, pp. 1063-1071, 2011

[12] H. Liu., S. Zhang, S. Zhang, "Fuzzy Expert System Based Intelligent Website Assessment System”, IEEE 10th International Conference on Computer and Information Technology (CIT 2010), pp. 432-437, Bradford, United Kingdom, June 29-July 1, 2010

[13] F. Kong, H. Liu, “Applying fuzzy analytic hierarchy process to evaluate success factors of e-commerce” , International Journal of Information and Systems Sciences, Vol. 1, No. 3-4, pp. 406-412, 2005

[14] A. Albuquerque, A. Belchior, "E-Commerce Website Quality Evaluation”, 28th Euromicro Conference, pp. 294-300, Dortmund, germany, September 4-6, 2002

[15] S. Cebi, "A quality evaluation model for the design quality of online shopping websites", Electronic Commerce Research and Applications, Vol. 12, No. 2, pp. 124-135, 2013

[16] H. Singh, M. Gupta, T. Meitzler, Z. Hou, K. Garg, A. Solo, L. Zadeh, "Real-Life Applications of Fuzzy Logic", Advances in Fuzzy Systems, Vol. 2013, Article ID 581879, 2013

[17] G. Klir, B. Yuan, Fuzzy Sets and Fuzzy Logic: Theory and Applications, Prentice Hall, 1995

[18] L. Zadeh, “Fuzzy Sets”, Information and Control, Vol. 8, No. 3, pp. 338353, 1965

[19] L. Zadeh, “Is there a need for fuzzy logic?”, Information Sciences, Vol. 3, No. 3, pp. 2751-2779, 2008 